Research Article

\title{
Time-Resolved Emission Spectroscopy Measurements during the Restrike Period in Arc Plasma Torch
}

\author{
Alan Mašláni iD, ${ }^{1}$ Peter Ondáč, ${ }^{1,2}$ Viktor Sember, ${ }^{1}$ and Milan Hrabovský ${ }^{1}$ \\ ${ }^{1}$ Institute of Plasma Physics, Za Slovankou 3, 18200 Prague, Czech Republic \\ ${ }^{2}$ Department of Surface and Plasma Science, Faculty of Mathematics and Physics, Charles University, V Holešovičkách 2, \\ 18200 Prague, Czech Republic
}

Correspondence should be addressed to Alan Mašláni; maslani@ipp.cas.cz

Received 31 January 2018; Revised 11 May 2018; Accepted 3 June 2018; Published 4 July 2018

Academic Editor: Arnaud Cuisset

Copyright (C) 2018 Alan Mašláni et al. This is an open access article distributed under the Creative Commons Attribution License, which permits unrestricted use, distribution, and reproduction in any medium, provided the original work is properly cited.

Simultaneous optical, spectroscopic, and electrical measurements in the region of the arc anode attachment of the water-argon plasma torch are presented. A movement of the arc attachment along the anode surface together with its restrike mode is monitored. Temporal evolution of temperature during one cycle of the restrike mode is obtained in three different axial positions in the plasma column. Resulting temperature profiles show how the position of the arc attachment influences the plasma properties.

\section{Introduction}

Measurement of plasma characteristics with high temporal and spatial resolution is of great importance in order to understand physics of the individual discharge as well as for various applications in plasma processing technologies. Time-resolved measurements are typical for discharges with well-defined temporal appearance, that is, different types of $\mathrm{AC}$ and pulsed discharges. It is possible to find such cases also for arc discharges, which are of special interest in relation to the present work [1-3]. As for DC discharges, measurements with high temporal resolution are less frequent because it is often not expected any specific temporal behaviour of such discharges in the timescales of interest.

In case of optical diagnostic, one of the issues is a type of detector used for collection of radiation. CCD sensors give a possibility to reach high spatial and/or spectral resolution; however, they have limits in studying of temporal behaviour. Although CCD-based high-speed cameras are still more frequently used and also their speed quickly increases, they are still relatively expensive. Nevertheless, attempts to combine high-speed CCD and spectroscopy measurements have been done exactly on the arc discharges $[4,5]$. On the other hand, photomultipliers offer usually well temporal but lower spatial and spectral resolution. Photomultipliers are also much more sensitive than CCDs; therefore, they are suitable also for very low light measurements. In this work, we encounter limits of used CCD sensor, namely, the temporal resolution of spectroscopic measurements.

In case of DC arc discharges, the well-known timeresolved pattern described in the literature is the so-called restrike mode of the anode attachment (also called arc root) movement in plasma torches $[6,7]$. Restrike mode is characterized by sudden appearance of arc attachment in the upstream position of the anode. Then, the attachment moves along the anode downstream of the plasma flow until the next restrike occurs. Typically, the anode has a shape of a hollow cylinder; attachment moves in an inner surface of this cylinder in three dimensions, and the period of this movement is not well defined. However, in this work, we study the plasma torch in which the anode is disc shaped; thus, the attachment moves along the outer surface of this disc in one dimension only. As a result, the periodicity of the restrike mode is much better than in the case mentioned above. Then, we are able to use this period in order to obtain the time-resolved spectroscopic characterization of one cycle of the restrike. Combination of these spectroscopic measurements with high-speed camera movies and time-resolved 


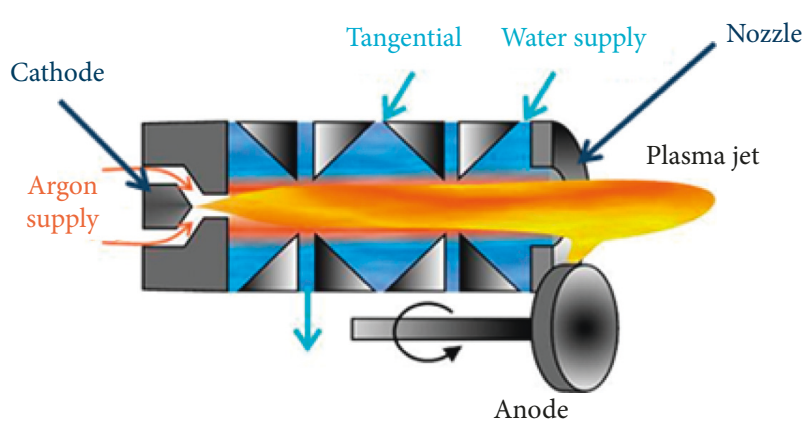

(a)

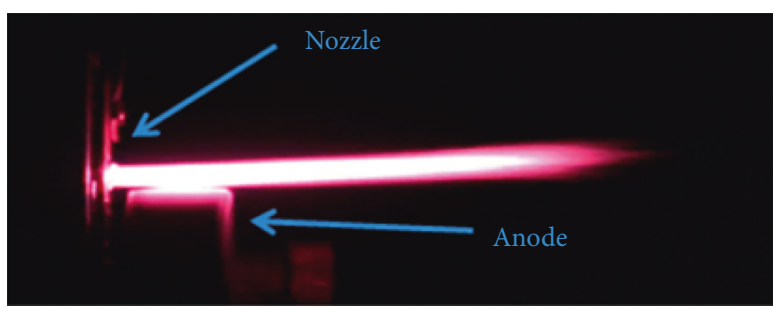

(c)

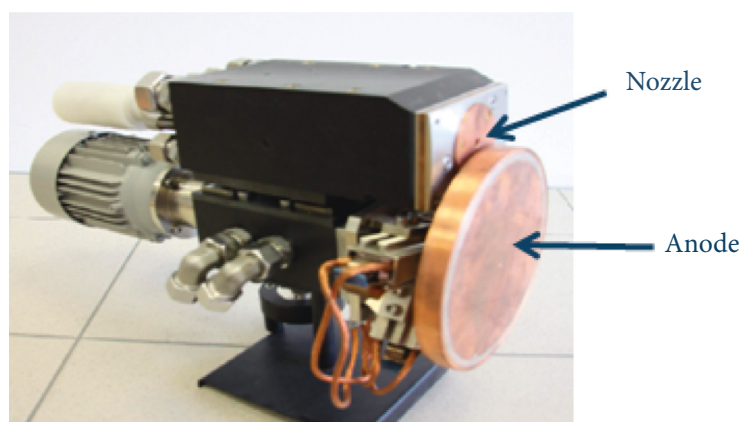

(b)

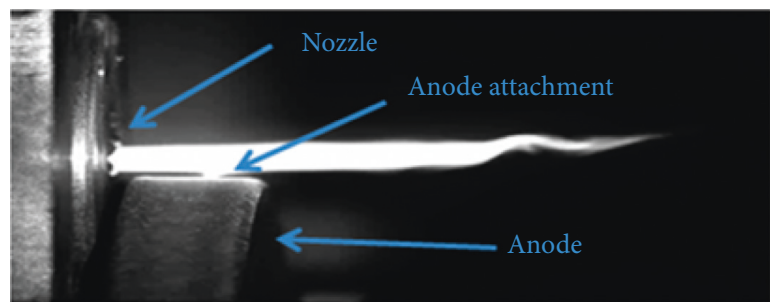

(d)

FIGURE 1: Water-argon plasma torch and jet: (a) schematic view of the torch, (b) photograph of the torch, (c) image of the plasma jet (camera (Canon EOS 450D), exposure time in the order of milliseconds), and (d) image of the plasma jet (high-speed camera (Photron), exposure time in the order of microseconds). Images were taken at the arc current $500 \mathrm{~A}$ and argon flow rate $12 \mathrm{slm}$.

measurement of the cathode-anode voltage brings new insight into the arc phenomena in the thermal plasma torches.

The last topic relevant to this work is an analysis of optical emission spectra and consideration of local thermodynamic equilibrium (LTE). Generally saying, LTE conditions are supposed to be valid in DC arc plasmas with good accuracy; therefore, these plasmas are often given as examples of thermal plasmas [8]. The departures from LTE are reported only in outer parts of the arcs, in recombining jets, and in electrode regions [7, 9, 10]. In this work, spectroscopic measurement in the anode region of the arc is performed and LTE validity is assumed. Therefore, we should be aware of the correct interpretation of the results especially from the point of view of electrode phenomena.

First, preliminary results dealing with time-resolved emission spectroscopy in the anode area of the waterargon plasma torch were already published [11]. In comparison with those results, this paper brings new and more detailed data together with their proper interpretation and analysis.

\section{Experimental Setup}

Plasma source used in this work is the so-called hybrid DC water-argon torch, which was developed on the base of the previously studied water-stabilized torch. The hybrid torch has been successfully applied for plasma spraying [12] as well as for gasification of various organic substances [13, 14]. Details about this torch can also be found elsewhere $[15,16]$. Schematic view of the hybrid torch and its photo are shown in Figures 1(a) and 1(b). The arc is stabilized by the argon in the cathode region and by the water vortex surrounding substantial part of the arc column. The arc current can be varied between $200 \mathrm{~A}$ and $600 \mathrm{~A}$ and the argon flow rate between $8 \mathrm{slm}$ and $40 \mathrm{slm}$. The rate of water evaporation into the plasma is about $0.3 \mathrm{~g} / \mathrm{s}$. This work presents measurements for $500 \mathrm{~A}$ and for $12 \mathrm{slm}$ of argon. The cathodeanode voltage reaches about $280 \mathrm{~V}$, which gives the arc power $140 \mathrm{~kW}$.

A cathode, made of thoriated tungsten, is protected by the argon flow; therefore, its erosion is negligible and its lifetime is long. The anode is a copper disc with the thickness $16 \mathrm{~mm}$ which is rotating with the frequency $50 \mathrm{~Hz}$ in order to assure uniform erosion. Moreover, the anode is cooled by water circulating in its partly hollow body. The anode is located outside of the torch, in the distance $2 \mathrm{~mm}$ from the exit of the nozzle in the horizontal direction.

The gap of the nozzle connecting arc chamber with the surrounding environment has $6 \mathrm{~mm}$ diameter. From this description and from Figure 1, it is evident that we are able to observe part of the arc between nozzle and anode, and also the arc attachment which is moving along the anode surface with the period in the order of tens of microseconds. Typical photographs of the plasma jet taken by a common camera and by a high-speed camera are shown in Figures 1(c) and 1(d). It is possible to see that the common camera with exposure times in milliseconds does not reveal any details in the anode region. On the other hand, high-speed camera with exposure times in microseconds clearly shows the anode attachment and is able to follow its movement.

The measurement system consists of high-speed camera (Photron), voltage probe (Rigol), PC oscilloscope (PicoScope), and spectrometer (Jobin-Yvon Triax 552). Videos recorded by the high-speed camera are synchronized with the cathodeanode voltage measurements and with spectroscopic measurements. 


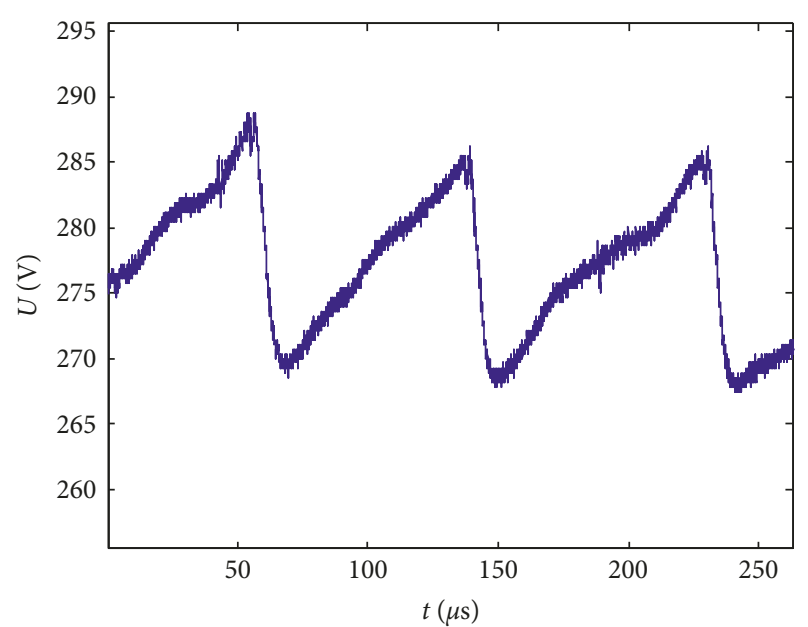

Figure 2: Example of the temporal evolution of the cathode-anode voltage.

\section{Description of Measurement}

We present measurements for the arc current $500 \mathrm{~A}$ and argon flow rate $12 \mathrm{slm}$. Figure 2 shows a sawtooth pattern of cathode-anode voltage, which is typical for restrike mode of the arc attachment movement along the anode surface. Figure 3 shows images of the plasma obtained by the highspeed camera corresponding approximately to a minimum (Figure 3(a)) and maximum (Figure 3(b)) cathode-anode voltage. The voltage monotonically increases from minimum to maximum as the arc attachment moves along the anode downstream of the plasma flow. When the attachment reaches the end of the anode, it disappears, conducting connection between the plasma flow and anode is interrupted, and new attachment is formed upstream. This event is accompanied by a fast drop of the voltage. Thus, the new cycle of arc attachment movement begins and the process repeats. The full sequence of images characterizing this process is shown in Figure 4. In this case, images come from the high-speed movie with the frame rate $300,000 \mathrm{fps}$. For such high temporal resolution, only small window with anode region of the plasma column is visible (anode is in the bottom part of images).

Figure 3 shows also positions in which we performed spectroscopic measurements; they are marked by the red rectangles and by numbers 1,2 , and 3 . In position 1 , light is collected from the arc plasma close to the exit of the torch nozzle; it means that measurement is not directly affected by the transition of the arc attachment through the field of view of the slit. Position 2 is above the central part of the anode, and in position 3 , we measure region above the downstream edge of the anode surface. In all measurements, the integration time of the spectra is $10 \mu \mathrm{s}$; as a typical period of the restrike is about $80 \mu \mathrm{s}$, we are able to monitor temporal behaviour during this period spectroscopically. In fact, integration time of $10 \mu \mathrm{s}$ is the shortest possible time, which gives reasonable results. For shorter times, the signal-tonoise ratio of obtained spectra is too low. One more feature of these measurements is that we collect light from the whole
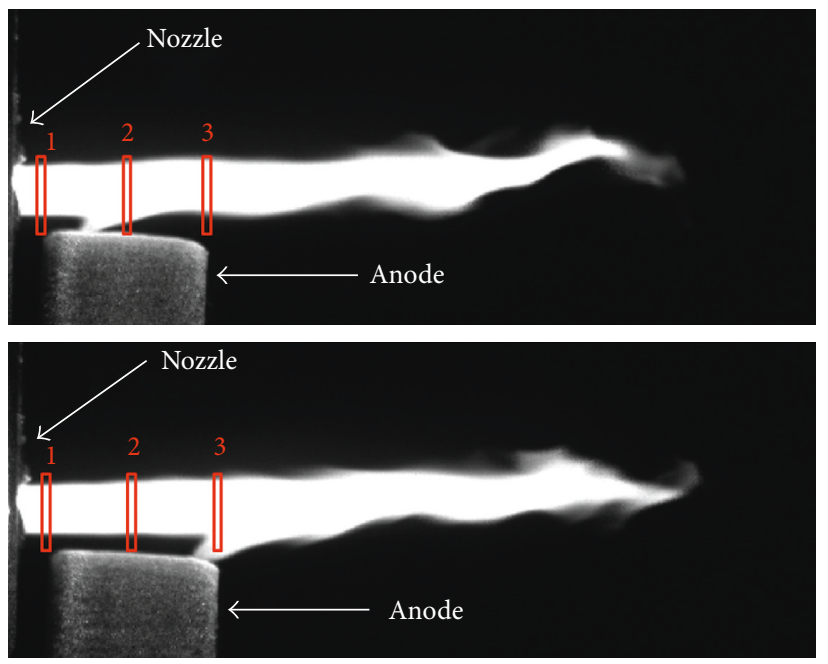

FIgURE 3: High-speed camera images of the plasma arc and jet for two cases: minimum voltage (a) and maximum voltage (b). Images come from a high-speed movie with $20,000 \mathrm{fps}$; exposure time is $1 \mu \mathrm{s}$. Red rectangles show positions of the entrance slit for spectroscopic measurements.

plasma column in a given axial distance. The summary is that, with given experimental setup and using CCD detector, we are able to measure spectra with temporal resolution given by minimum integration time of $10 \mu$ s and with spatial resolution in one dimension given by the distance from the exit of the torch nozzle. On the other hand, in our previous studies, we investigated spectra with high spatial resolution but integrated during timescales of tens of milliseconds $[17,18]$. In such a way, we obtained local values of temperatures in different parts of the arc column, but temporal resolution did not allow following the arc attachment movement.

Figure 5 shows typically measured emission spectra in a spectral window with the centre near $\mathrm{H} \beta$ line $(486.1 \mathrm{~nm})$. In spite of the fact that, using given integration time $10 \mu \mathrm{s}$, the spectra are noisy, it is possible to see well-recognized and broad $\mathrm{H} \beta$, as well as four emission lines of singly ionized argon $(472.7,473.6,476.5$, and $480.6 \mathrm{~nm}$ ). All these lines were used for temperature determination. We supposed that the plasma is optically thin for all these lines. Such assumption is usually valid for arc plasmas of these dimensions in this spectral region. The method is based on the ratio of experimental and theoretical emission coefficients of $\mathrm{H} \beta$ and ArII lines; a detailed description of this method can be seen in [19]; then, the method was further used for the characterization of the plasma produced by the same torch as in this work [18]. The method uses the fact that the plasma composition in the arc is known-water and argon. Then, equilibrium composition of plasma as a function of temperature can be calculated. From the composition, emission coefficients corresponding to individual transitions can be obtained theoretically, and from measured emission spectral lines, we also have them experimentally. Comparison of experimental and theoretical emission coefficients (and their ratios) gives the temperature. More specifically, the most suitable quantity for temperature determination is the ratio 

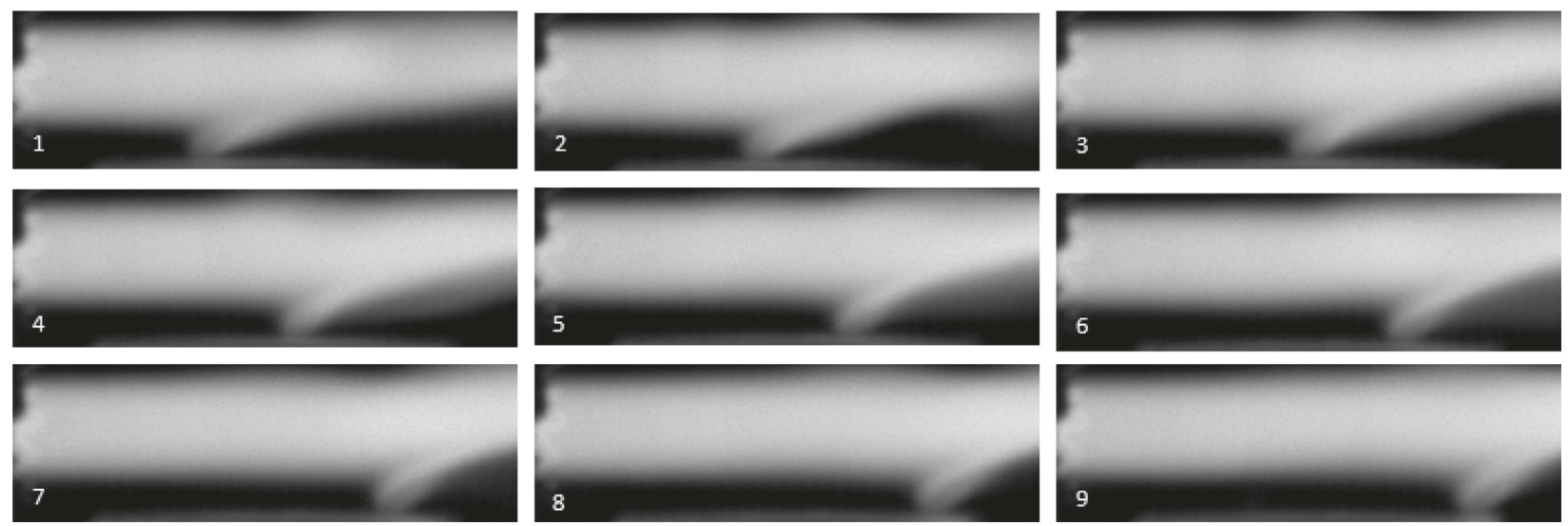

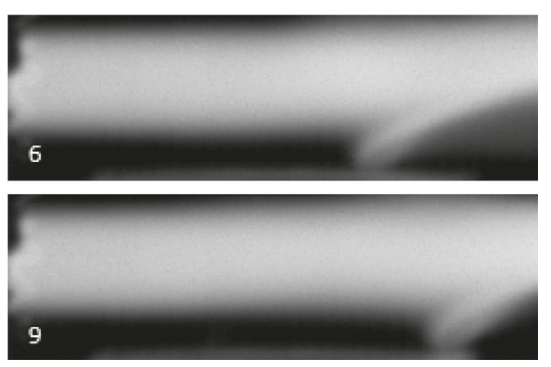

Figure 4: A sequence of images covering one period of the restrike process. Images come from a high-speed movie with $300,000 \mathrm{fps}$; exposure time is $0.29 \mu \mathrm{s}$.
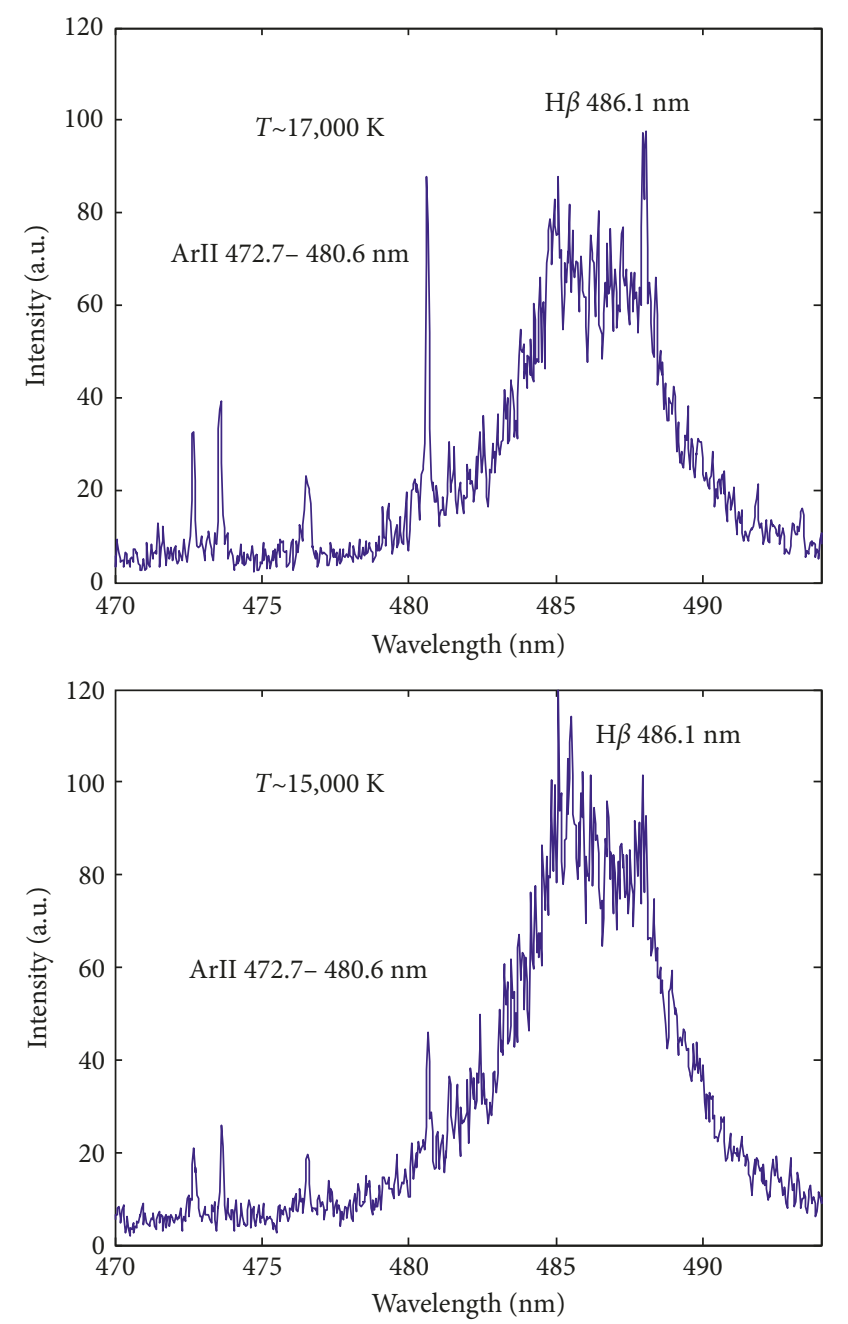

FIgURE 5: Typical emission spectra with the central wavelength near $\mathrm{H} \beta$ line. The ratio of intensities of $\mathrm{H} \beta$ to ArII lines is apparently different when the temperature is $17,000 \mathrm{~K}$ (a) and $15,000 \mathrm{~K}$ (b).

of the maximum of $\mathrm{H} \beta$ line and total emission coefficient of four ArII lines. This ratio is very sensitive to temperature and requires only relative calibration of spectral response.
The advantage of this method is that one spectral window from $470 \mathrm{~nm}$ to $500 \mathrm{~nm}$ gives enough information to obtain temperature reliably. Comparison of two spectra in Figure 5 shows that the ratio of intensities of $\mathrm{H} \beta$ and ArII lines is suitable for temperature determination in the approximate range from $15,000 \mathrm{~K}$ to $17,000 \mathrm{~K}$, which is reached in these experiments.

Spectroscopic measurements were performed as follows: for given position of the measurement, we captured a large number of spectra together with high-speed camera movies and temporal dependence of voltage. From these data, we chose only those, which did not include the restrike process itself. Comparison of movies and voltage dependence specifies in which moment during restrike period the spectrum was measured. Camera movies and voltage dependence have temporal resolution with the frame rate $300,000 \mathrm{fps}$ and the sampling rate $80 \mathrm{MHz}$, respectively. Therefore, identification of moment of capture of each spectrum is well exact. Finally, we excluded those data that were measured during periods, which were much longer or shorter than the average one $(80 \mu \mathrm{s})$. As a result, we obtained the temporal profile of temperature during the average restrike period.

\section{Results and Discussion}

Results are shown in Figures 6-8. Each point in these temporal profiles corresponds to the centre of the time interval during which spectra were acquired. As was mentioned above, the integration time of each measurement is $10 \mu \mathrm{s}$. It means, for instance, that point with time coordinate $40 \mu \mathrm{s}$ was measured in the time interval from $35 \mu \mathrm{s}$ to $45 \mu \mathrm{s}$. Time zero corresponds to the moment just after restrike process; that is, it is the moment with minimum voltage when anode attachment is closest to the exit nozzle of the torch (Figure 3(a)). Similarly, at the time $80 \mu \mathrm{s}$, there is a maximum voltage (Figure 3(b)).

Temperatures measured in position 1 are shown in Figure 6. It means that we measure in the arc column close to the exit of the nozzle of the torch. We can observe a monotonic increase in temperature during the period of 

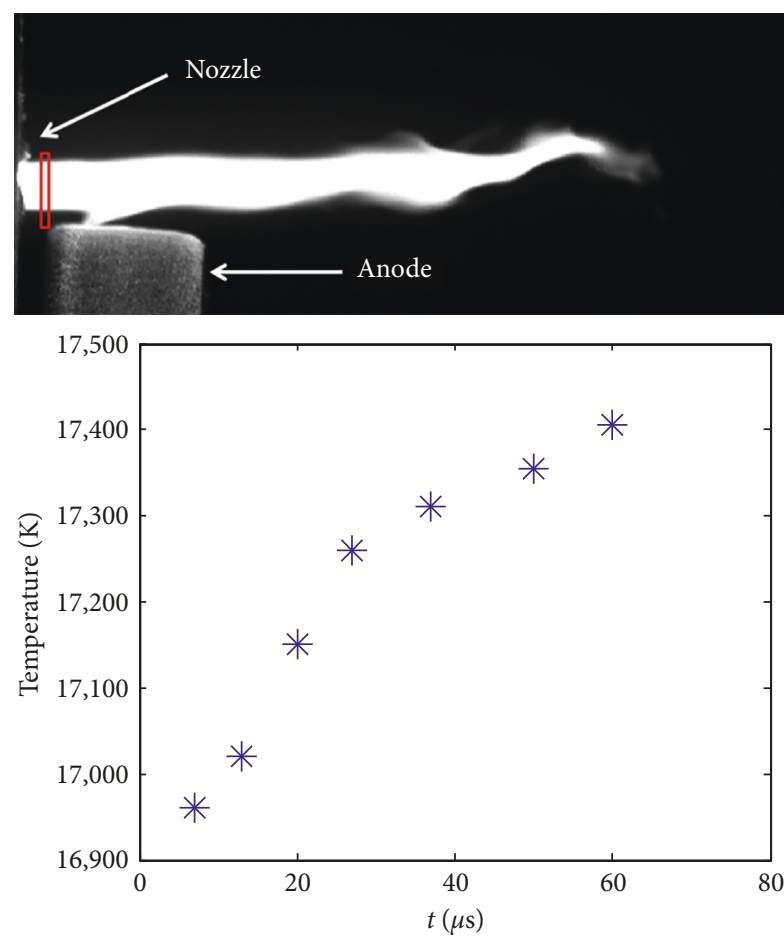

FIGURE 6: Temporal evolution of temperature during one period of restrike mode (measured in position 1 as shown by the red rectangle in high-speed camera image above the graph).

arc attachment movement. Figure 7 presents measurement in position 2 (above the centre of the anode). In this case, the temperature reaches its maximum value in the middle of the time interval at about $40 \mu$ s. Finally, Figure 8 shows the results of temperature measurement in position 3 , where temperature again monotonically increases up to the maximum value at the end of the interval.

Interpretation of these results is not straightforward. As for position 1 , we measure in the arc column without the direct influence of anode processes. However, the length of the arc and therefore also the distance of the measurement from the arc anode attachment change during the restrike period. It is known that temperature distribution in the arc column is generally such that the maximum temperature is in the region between the electrodes from which temperature decreases with approaching to electrodes [20-22]. For this torch, we do not have experimental data of this type, but according to numerical models, such dependence along the axis of the torch is also present [23,24]. Such temperature distribution can simply explain the dependence as shown in Figure 6; as the arc attachment moves downstream, the position of measurement gets closer to the centre of the arc where the temperature is higher. The assumption is that LTE approximation is valid, which is highly probable for given conditions. Another assumption, which is less clear, is connected with the shape of the temperature distribution function along the arc column for different arc lengths. We must suppose that this function is approximately the same for different lengths of the arc during the restrike period, and moreover, gradient of temperature in a relatively short distance $(10-15 \mathrm{~mm})$ must be measurable by means of emission spectra. Then, the abovementioned
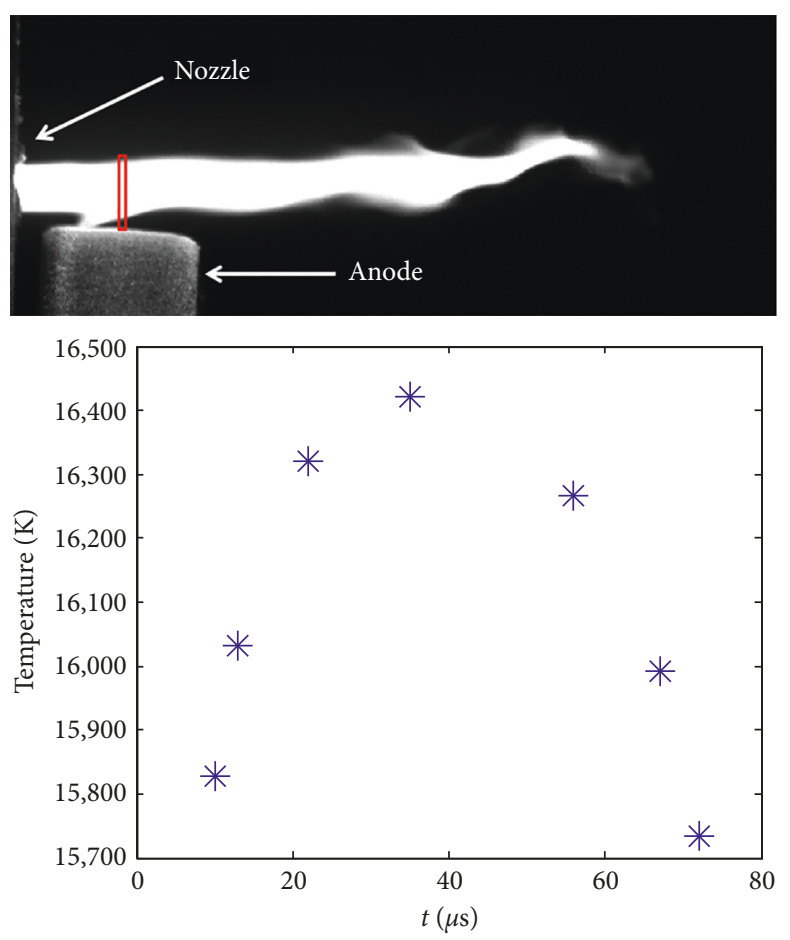

FIgURE 7: Temporal evolution of temperature during one period of restrike mode (measured in position 2 as shown by the red rectangle in high-speed camera image above the graph).
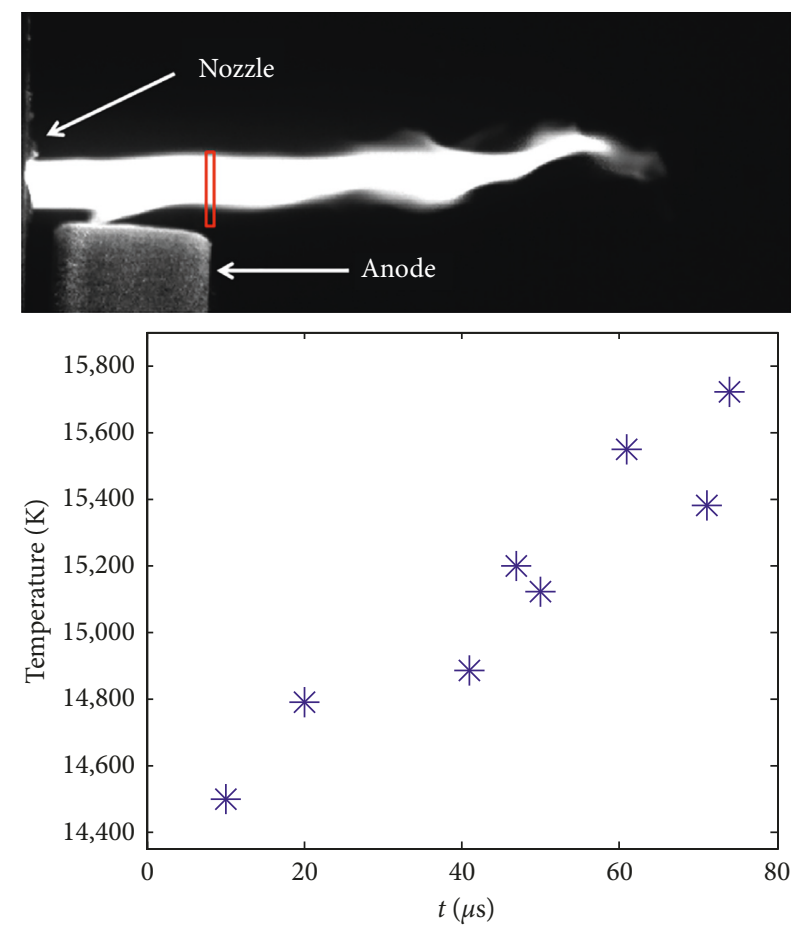

FIgURE 8: Temporal evolution of temperature during one period of restrike mode (measured in position 3 as shown by the red rectangle in high-speed camera image above the graph).

explanation of temperature profile can be valid. It is evident that detailed knowledge of this function is necessary to give higher credibility to this explanation. 
For measurements in positions 2 and 3, it seems that maximum value is connected with the presence of the arc attachment. As it moves along the centre of the anode surface, the maximum temperature is measured (Figure 7). Similarly, the highest temperature at the edge of the anode is obtained at the moment when arc attachment gets there (Figure 8). The region of anode attachment is characterized by the interaction of plasma with the solid electrode. This phenomenon brings strong nonequilibrium effects into the thermal arc plasma behaviour [7]. We can thus simply claim that increase of the temperature in the moments with arc attachment in the field of view of spectroscopic diagnostic is connected with violation of LTE, and then, this temperature does not represent kinetic temperature.

About the measurement in position 2, we can also say that it takes place on both sides of the arc attachment, that is, downstream and upstream of the attachment. In principle, it is expected that the temperature should decrease downstream of the arc attachment in the direction of the freely expanding jet, and on the other hand, temperature should increase in the upstream direction inside the arc. However, Figure 7 does not prove this assumption, which can be explained by the fact that measurement takes place in close vicinity (few millimeters) of the attachment, and thus, nonequilibrium effects dominate in this case. On the other hand, in position 1, we get far enough from the attachment in order to register temperature profile inside the arc. In any case, only higher temporal and spatial resolution of measurement can bring more details into the temperature distributions around the arc attachment.

Regarding the measurement in position 3, its interpretation is probably not so complicated. At the outer edge of the anode, we are most of the time downstream of the arc where recombining jet begins. The temperature in this region is naturally lower than that in the arc. As the arc attachment approaches, the temperature grows. Then, both effects, approaching of the hot arc region and influence of the nonequilibrium near the attachment, can cause the increase in temperature during the restrike period.

We can also say something about the range of measured temperatures in Figures 6-8, which is from approximately $14,500 \mathrm{~K}$ to $17,500 \mathrm{~K}$. This range is relatively narrow and can bring questions about the accuracy of the method. The fact is that temperature gradients in arcs are quite strong. However, our measurements are averaged through the whole plasma column in a given axial distance. Therefore, measured averaged temperatures cannot be easily compared with local values of temperatures, which show these strong gradients. Anyway, rough estimation can be done: temperature on the axis of this torch in the arc region for given conditions is above $20,000 \mathrm{~K}$, while in the $3 \mathrm{~mm}$ radial distance, which is the edge of the luminous arc, the temperature decreases to about $12,000 \mathrm{~K}[16]$. Then, the average temperatures measured in this work may be correct and also obtained temporal profiles may be reliable. As was mentioned in Section 3 , the sensitivity of the method is very high; the variations of temperature in the order of $\sim 100 \mathrm{~K}$ have a clear effect on the $\mathrm{H} \beta /$ ArII ratio (in the temperature range of interest). Systematic error arising from not exactly known concentrations of species can only influence absolute value of temperature (we suppose uncertainty of this absolute value about $10 \%$ ). However, under the assumption that these concentrations are constant in all three measured positions and in all measured time instants, the changes in spectra can be attributed to temperature changes.

Finally, some comments on thermodynamic equilibrium validity can be added. As was mentioned earlier, the LTE conditions are usually well valid in central parts of highintensity arc plasmas. This is also the case of the plasma torch used in this research; it was shown that necessary conditions for LTE validity, such as Griem's or McWhirter's criteria, are well fulfilled in the arc region as well as downstream in recombining jet [18]. However, these criteria are not sufficient; in spite of their validity, the departure from LTE can be additionally caused, simply saying, by inhomogeneity and/or transient nature of the plasmas, as summarized in the work of Cristoforetti et al. [25]. The region of arc attachment is characterized not only by high electron density but also by strong inhomogeneity of the plasma. This can be the reason of overestimation of the temperature in this region. One more observation deduced from Figures $6-8$ is that temperatures monotonically decrease from position 1 to position 3. For example, if we choose time $10 \mu \mathrm{s}$, we have almost a linear decrease of these temperatures in this sequence of positions $(\sim 17,000 \mathrm{~K}, \sim 15,800 \mathrm{~K}$, and $\sim 14,500 \mathrm{~K})$. Presence of anode attachment does not change the monotonic character of this dependence, but it makes this decrease nonlinear (the most extreme example is $\sim 17,400 \mathrm{~K}, \sim 15,700 \mathrm{~K}$, and $\sim 15,600 \mathrm{~K}$ for time $70 \mu \mathrm{s})$. It means that the most important factor for the temperature value and its variations is still the presence of arc current path, while the non-LTE behaviour only modulates these changes.

\section{Conclusion}

Time-resolved measurements of arc discharge in the anode region are presented. We were able to follow the movement of the arc anode attachment using high-speed camera movies and arc voltage time evolution as well as by emission spectra. Results include the temporal evolution of temperature during one cycle of the restrike mode. It is shown that temperature in a given axial distance depends on the position of the arc attachment.

Presented measurement can be considered as one of the first measurements of this type. It seems to be natural that higher temporal and spatial resolution at the same moment will bring better insight into the studied phenomena. Therefore, enhancement of the diagnostic apparatus in order to reach this goal is planned as a next step.

\section{Data Availability}

Data are available on request from the authors.

\section{Conflicts of Interest}

The authors declare that they have no conflicts of interest. 


\section{Acknowledgments}

This work was supported by the Czech Science Foundation (GACR) under Project GC17-10246J.

\section{References}

[1] M. Tanaka, T. Ikeba, Y. Liu, S. Choi, and T. Watanabe, "Investigation of electrode erosion mechanism of multi-phase AC arc by high-speed video camera," Journal of Physics: Conference Series, vol. 441, article 012015, 2013.

[2] M. Kühn-Kauffeldt, J.-L. Marqués, and J. Schein, “Thomson scattering diagnostics of steady state and pulsed welding processes without and with metal vapor," Journal of Physics D: Applied Physics, vol. 48, no. 1, article 012001, 2015.

[3] J. Hlína, J. Šonský, J. Gruber, and Y. Cressault, "Fast tomographic measurements of temperature in an air plasma cutting torch," Journal of Physics D: Applied Physics, vol. 49, no. 10, article 105202, 2016

[4] B. Bachmann, R. Kozakov, G. Gött et al., "High-speed threedimensional plasma temperature determination of axially symmetric free-burning arcs," Journal of Physics D: Applied Physics, vol. 46, no. 12, article 125203, 2013.

[5] D. Uhrlandt, R. Methling, S. St. Franke Gorchakov, M. Baeva, A. Khakpour, and V. Brüser, "Extended methods of emission spectroscopy for the analysis of arc dynamics and arc interaction with walls," Plasma Physics and Technology, vol. 2, no. 3, pp. 280-289, 2015.

[6] S. Paik, P. C. Huang, J. Heberlein, and E. Pfender, "Determination of the arc-root position in a DC plasma torch," Plasma Chemistry and Plasma Processing, vol. 13, no. 3, pp. 379-397, 1993.

[7] J. Heberlein, J. Mentel, and E. Pfender, "The anode region of electric arcs: a survey," Journal of Physics D: Applied Physics, vol. 43, no. 2, article 023001, 2010.

[8] V. Helbig, "Diagnostics of thermal plasma," Pure and Applied Chemistry, vol. 60, no. 5, pp. 675-684, 1988.

[9] L. E. Cram, L. Poladian, and G. Roumeliotis, "Departures from equilibrium in a free-burning argon arc," Journal of Physics D: Applied Physics, vol. 21, no. 3, pp. 418-425, 1988.

[10] J. Haidar, "Departures from local thermodynamic equilibrium in high-current free burning arcs in argon," Journal of Physics D: Applied Physics, vol. 30, no. 19, pp. 2737-2743, 1997.

[11] A. Mašláni, P. Ondáč, V. Sember, and M. Hrabovský, “Timeresolved optical and spectroscopic study of the restrike mode in arc plasma torch," in Proceedings of the ISPC 2017: 23rd International Symposium on Plasma Chemistry, Book of Extended Abstracts, pp. 640-642, International Plasma Chemistry Society, Montréal, Canada, 2017.

[12] T. Kavka, J. Matějíček, P. Ctibor, A. Mašláni, and M. Hrabovský, "Plasma spraying of copper by hybrid watergas DC arc plasma torch," Journal of Thermal Spray Technology, vol. 20, no. 4, pp. 760-774, 2011.

[13] M. Hrabovský, M. Hlína, M. Konrád et al., "Thermal plasma gasification of biomass for fuel gas production," High Temperature Material Processes, vol. 13, no. 3-4, pp. 299-313, 2009.

[14] M. Hrabovský, M. Hlína, V. Kopecký et al., "Steam plasma treatment of organic substances for hydrogen and syngas production," Plasma Chemistry and Plasma Processing, vol. 37, no. 3, pp. 379-397, 2017.

[15] M. Hrabovský, "Generation of thermal plasmas in liquidstabilized and hybrid dc-arc torches," Pure and Applied Chemistry, vol. 74, no. 3, pp. 429-433, 2002.
[16] M. Hrabovský, V. Kopecký, V. Sember, T. Kavka, O. Chumak, and M. Konrád, "Properties of hybrid water/gas DC arc plasma torch," IEEE Transactions on Plasma Science, vol. 34, no. 4, pp. 1566-1575, 2006.

[17] A. Mašláni and V. Sember, "Emission spectroscopy of $\mathrm{OH}$ radical in water-argon arc plasma jet," Journal of Spectroscopy, vol. 2014, Article ID 952138, 6 pages, 2014.

[18] A. Mašláni, V. Sember, and M. Hrabovský, "Spectroscopic determination of temperatures in plasmas generated by arc torches," Spectrochimica Acta Part B, vol. 133, pp. 14-20, 2017.

[19] V. Sember and A. Mašláni, "A simple spectroscopic method for determining the temperature in a $\mathrm{H}_{2} \mathrm{O}$-Ar thermal plasma jet," High Temperature Material Processes, vol. 13, no. 2, pp. 217-228, 2009.

[20] A. J. D. Farmer, G. N. Haddad, and L. E. Cram, "Temperature determinations in a free-burning arc: III. Measurements with molten anodes," Journal of Physics D: Applied Physics, vol. 19, no. 9, pp. 1723-1730, 1986.

[21] M. Razafinimanana, L. El Hamidi, A. Gleizes, and S. Vacquié, "Experimental study of the influence of anode ablation on the characteristics of an argon transferred arc," Plasma Sources Science and Technology, vol. 4, no. 3, pp. 501-510, 1995.

[22] P. Kah, H. Latifi, R. Suoranta, J. Martikainen, and M. Pirinen, "Usability of arc types in industrial welding," International Journal of Mechanical and Materials Engineering, vol. 9, no. 1, p. 15, 2014.

[23] J. Jeništa, H. Takana, H. Nishiyama et al., "Integrated parametric study of a hybrid-stabilized argon-water arc under subsonic, transonic and supersonic plasma flow regimes," Journal of Physics D: Applied Physics, vol. 44, article 435204, 2011.

[24] J. Jeništa, H. Takana, S. Uehara et al., "Modeling of inhomogeneous mixing of plasma species in argon-steam arc discharge," Journal of Physics D: Applied Physics, vol. 51, article 045202, 2018.

[25] G. Cristoforetti, A. De Giacomo, M. Dell'Aglio et al., "Local thermodynamic equilibrium in laser-induced breakdown spectroscopy: beyond the McWhirter criterion," Spectrochimica Acta Part B, vol. 65, no. 1, pp. 86-95, 2010. 

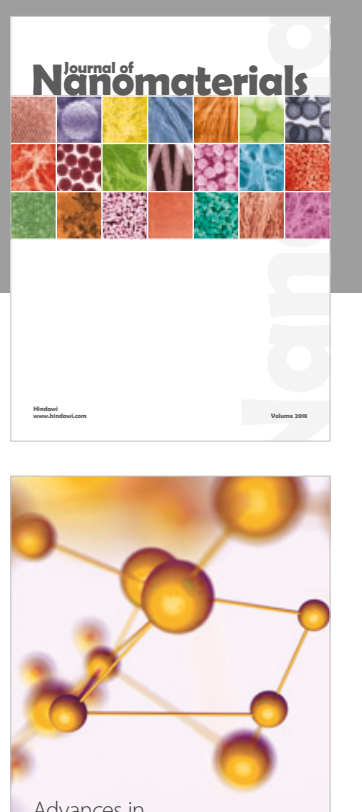

Physical Chemistry
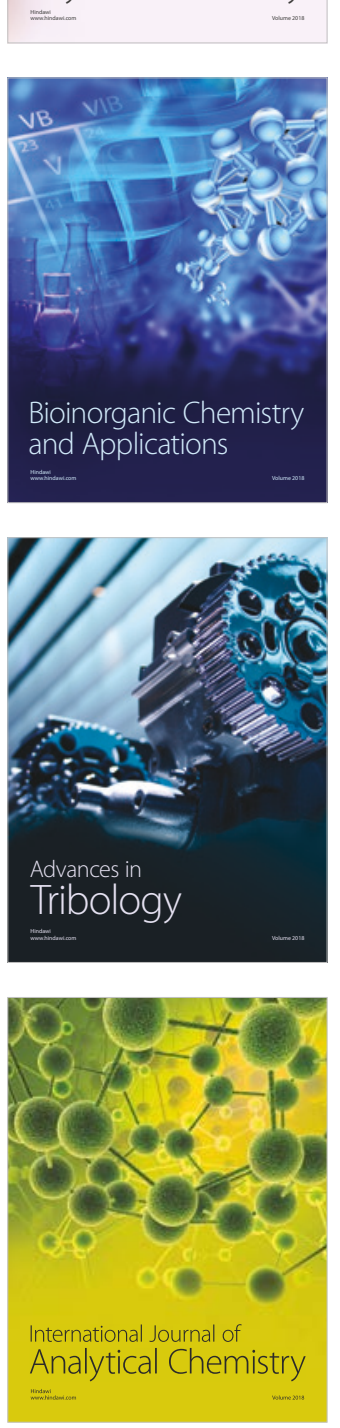

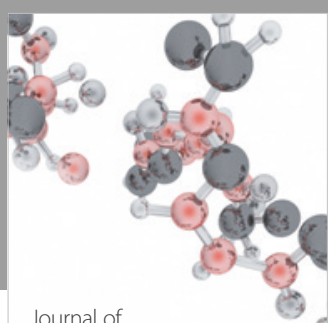

Analytical Methods

in Chemistry

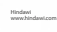

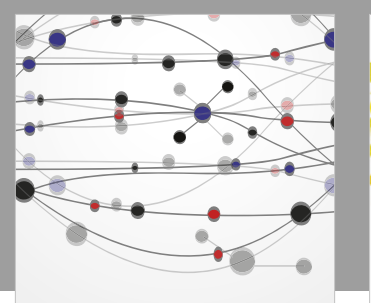

The Scientific World Journal

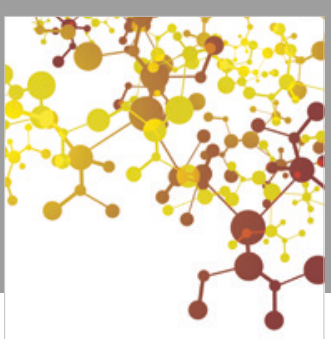

Journal of

Applied Chemistry
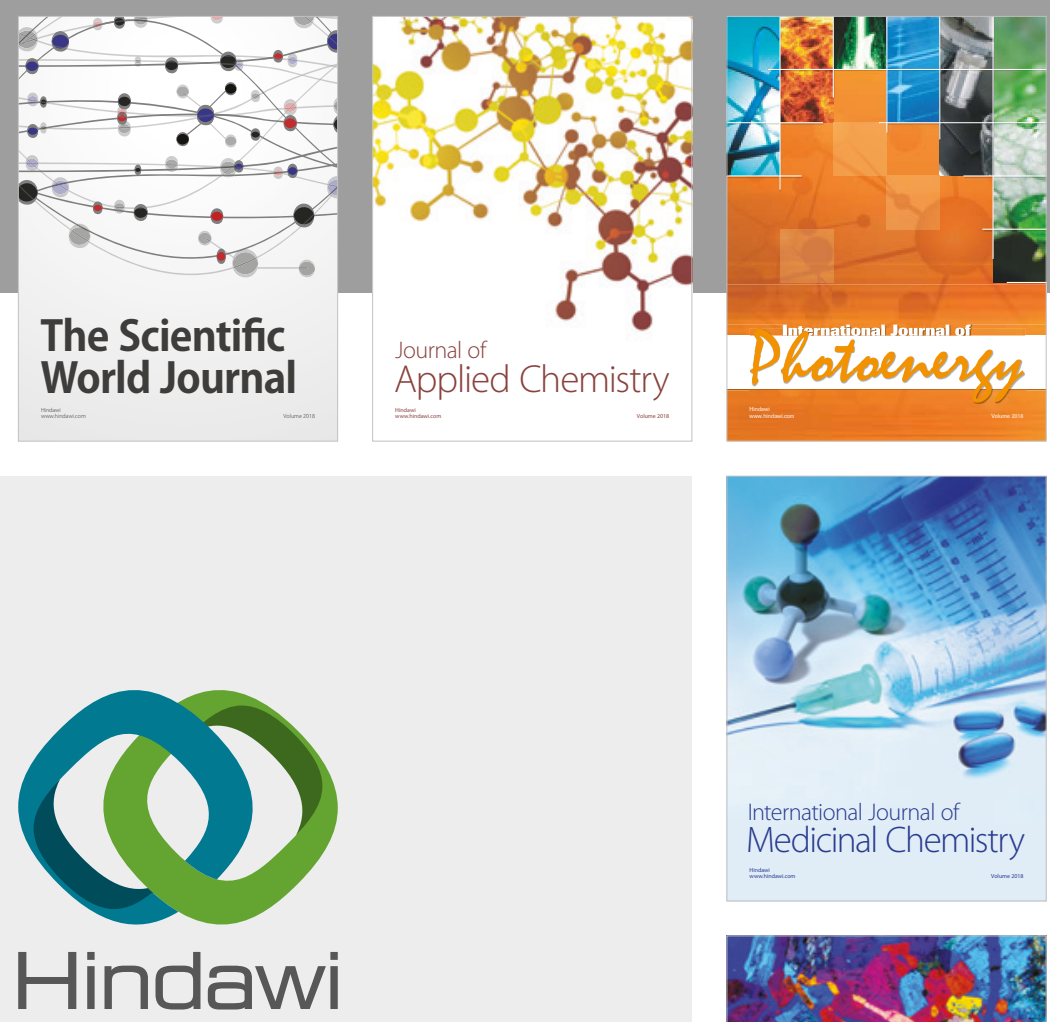

Submit your manuscripts at

www.hindawi.com
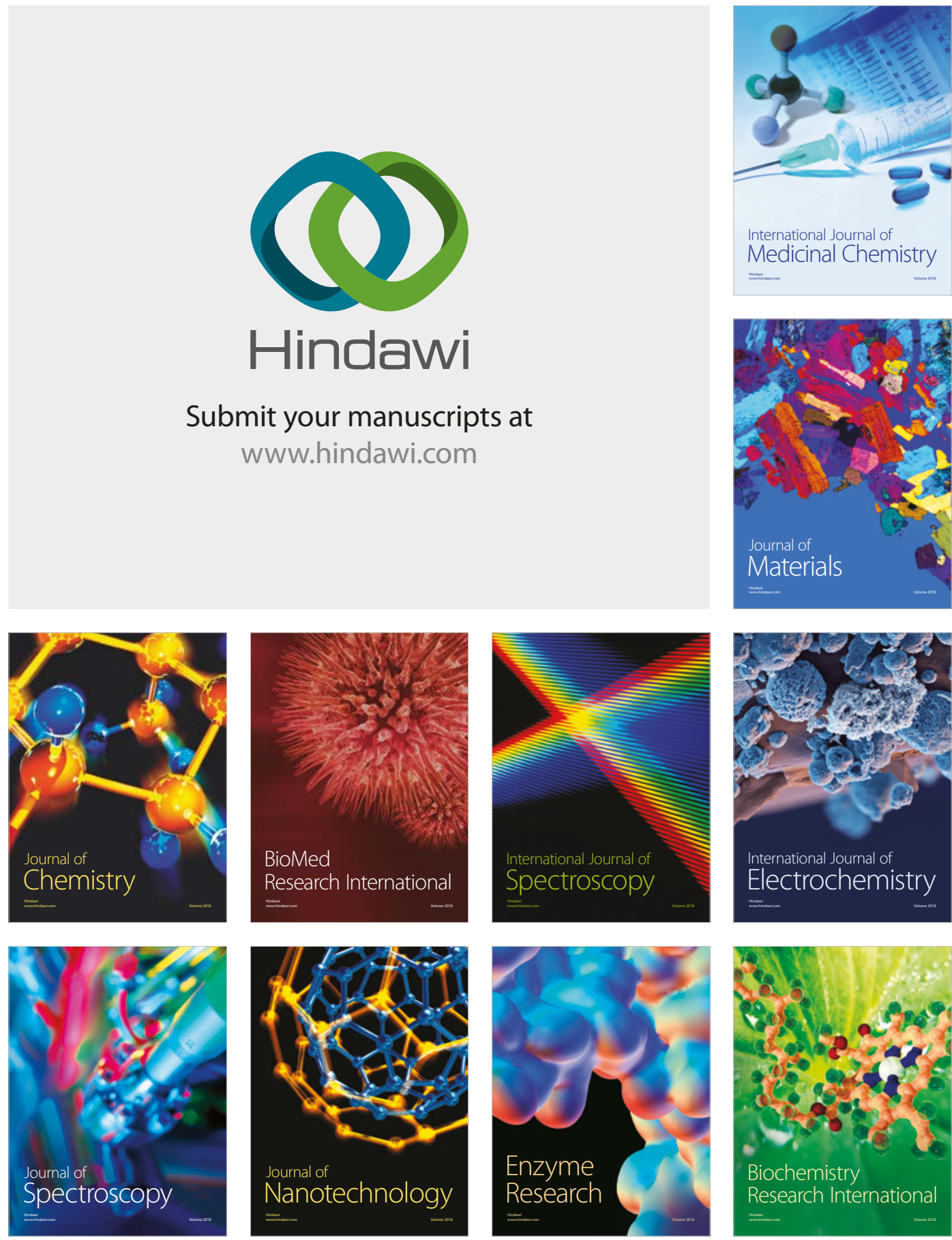
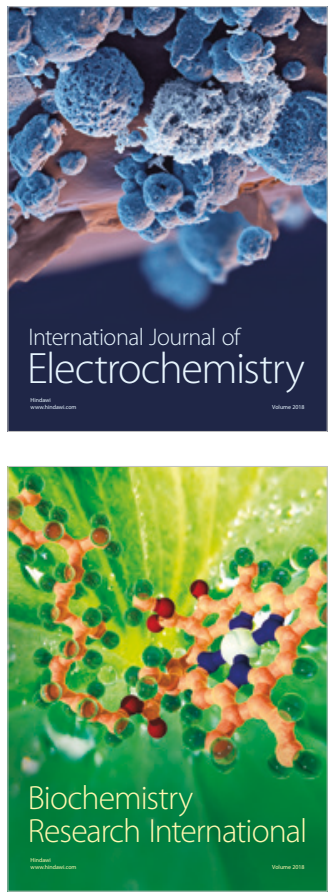